\title{
EL TÉRMINO CIENTÍFICO Y TÉCNICO Y EL DICCIONARIO ACADÉMICO
}

Un criterio bastante generalizado asigna al diccionario de la Academia la potestad de dar vida a las palabras. Quienes así piensan afirman que para que un vocablo "exista"' debe estar registrado en él. Hay otras personas que no exigen tanto, y se conforman con que aparezca en cualquier diccionario "de la lengua". En ambos casos, si no está es porque no existe.

Como consecuencia de lo anterior, también hay quienes echan pestes contra la Academia, la acusan de retrógrada, inepta, alejada de la realidad, etc., porque no recoge en su repertorio tal o cual palabra (en el caso que nos ocupa, propia de la ciencia o la técnica) "que todo el mundo conoce". Se da por sentado que ello es debido a que los académicos rechazan ese vocablo por considerarlo incorrecto (sea por su procedencia extranjera o por su formación u otra causa), o simplemente porque no se han enterado de su existencia.

En el fondo de estos criterios está la idea, también muy popularizada, de que el diccionario de la lengua debe recoger todas las palabras que en ella existen; según esto, mientras más vocablos registre mejor será el diccionario. Nada más falso: aun suponiendo que se pudieran inventariar todas las palabras de una lengua (por ejemplo, algunos han mencionado la cifra de medio millón de voces para el español), el resultado sería impublicable y, suponiendo que se publicara, sería poco práctico y no muy útil, por la cantidad enorme de registros innecesarios que contendría.

Es cierto que todo diccionario es un inventario de palabras, pero por necesidad es siempre restringido. El sistema léxico de cualquier lengua es abierto: constantemente está variando el número de sus componentes. El intento por recogerlos todos, aparte el excesivo volumen y la poca utilidad práctica señalados, tropieza de inmediato con varios obstáculos objetivos, tales como, en 
el orden sincrónico, el registro de voces poco usuales, propias de determinadas jergas o de regiones apartadas, la mayor parte de las cuales no presentan testimonio escrito que facilite su inventario. Añádase a ello la dificultad para establecer límites cronológicos a lo que se llamaría "la lengua actual": cualquier fecha que se tomara como convención podría ser considerada una arbitrariedad. Y, si se pretende la exhaustividad total, también diacrónica, la empresa adquiere ribetes de absurdo.

La idea de una codificación total del léxico sólo pudiera plasmarse en relación con una lengua muerta, y ello suponiendo que todo el vocabulario familiar, vulgar, popular y técnico de dicha lengua estuviera documentada en algún texto escrito, lo cual seguramente no sería real.

Al parecer, la empresa más ambiciosa que se ha llevado a efecto es la publicación, desde 1971, del Trésor de la langue française. Dictionnaire de la langue du XIX et du XX' siècle (1789-1960); esta obra, como indica su título, se plantea un límite temporal: ni lo anterior a la primera fecha, ni lo posterior a la segunda podría registrarse. A pesar de ello, tampoco es exhaustiva dentro del marco temporal impuesto: se le ha criticado que sólo contiene un $20 \%$ de términos técnicos y sólo cierta selección del vocabulario popular, vulgar y jergal, entre otros aspectos. Por lo general, este tipo de colección léxica se basa en el análisis de gran número de citas tomadas de textos escritos muy diversos, pero no en las manifestaciones de la lengua hablada.

De esta manera queda bien claro que el criterio de que el diccionario debe registrar "todo" no tiene fundamento válido.

La primera tarea de un diccionarista es plantearse sus límites, sean acertados o no. (Por convención decimos "diccionarista"; en rigor, el trabajo lexicográfico moderno ha de ser colectivo. Entiéndase, pues, que con la expresión "un diccionarista" nos referimos a un concepto plural.) Esos límites se basan en primer lugar en los intereses de un público determinado al cual va dirigida la obra. La validez de un diccionario está muy relacionada con el grado de acierto de los límites impuestos, y de la rigurosidad con que el autor se atenga a los requisitos que estableció para la selección de las voces. Desde luego, independientemente de los avances científicos y de la incorporación de medios electrónicos a la labor lexicográfica, siempre habrá algún resquicio para el subjetivismo en la selección del vocablo que se incorpora o que se desecha. 
Un escollo considerable en este empeño se presenta cuando se trata de determinar si una palabra debe aparecer en un diccionario general de la lengua o en uno especializado (de regionalismos, de hablas profesionales o especiales, técnico). A primera vista pudiera parecer sencillo, pero en realidad no lo es.

Desde luego, quienes se refieren a las "insuficiencias del diccionario" no se refieren a los de un tipo especial (aunque éstos también son criticados), sino a los más generales, a los "diccionarios de la lengua" (especialmente el académico), los que se supone que registran el significado de "las palabras que todo el mundo habla'. El problema, como se ha visto, está en establecer cuáles son esas palabras, y qué elementos forman, en realidad, el conjunto denominado "todo el mundo".

$\mathrm{Ni}$ la experiencia varias veces centenaria de la lexicografía tradicional, ni los avances de la moderna ciencia lexicográfica han sido capaces de erradicar por completo las insuficiencias (o los excesos) en la selección de las voces que componen un diccionario general. Puesto que es general, está dedicado al público más amplio; por tanto, debe contener el vocabulario común a todos los hablantes, suponiendo en ellos una base cultural común que sólo de manera ideal tiene existencia.

Mucho se ha discutido y se discute, pero lo cierto es que incluso los diccionarios tenidos como más completos (con todo el grado de relatividad que ello implica, como se ha visto) presentan debilidades, tanto por lo registrado como por lo dejado de registrar, pero también por el contenido de las definiciones, que pueden estar incompletas o mal enfocadas (lo que se evidencia más en los tecnicismos), o pueden no dejar bien delimitados los campos de aplicación de las acepciones. También el resto de la información (gramatical, sobre la combinabilidad, etc.) suele ser insatisfactorio.

Cuando se trata del vocabulario técnico que se ha de incorporar abundan las controversias. Al parecer, el criterio más generalizado para la inclusión de tecnicismos en los diccionarios generales es el de la difusión. Por lo común, se procura incorporar al diccionario general aquellos vocablos científicos y técnicos que dejan de ser patrimonio exclusivo de círculos de especialistas para pasar a formar parte de la competencia del hablante culto o semiculto promedio.

Descontando lo difícil que resulta actuar con toda exactitud al determinar la inclusión o exclusión de un tecnicismo en el diccionario general (está claro que sólo nos referimos a diccionarios 
elaborados con criterio científico), y lo engorrosos que pueden ser los estudios estadísticos que pudieran ofrecer datos más seguros, a estas dificultades se asocian fenómenos de no escasa relevancia que de ninguna manera pueden pasar inadvertidos:

a) No pocas voces del acervo común son a la vez términos propios de alguna actividad científica o técnica (calor, sal...).

b) Algunos términos científicos o técnicos amplían con el tiempo su significación a tal punto que se incorporan al lenguaje más general con un significado propio de este último, además del suyo (fenómeno, seno...).

c) Algunos términos científicos o técnicos llegan a hacerse tan comunes que para el público más general dejan de serlo (televisión, electricidad...).

d) Ocasionalmente, para nombrar un fenómeno nuevo, un descubrimiento, etc., se toma un vocablo del acervo común y se le asigna el nuevo significado técnico (partícula, paciente - en este caso, con cambio de categoría).

Por otra parte, la inclusión de un tecnicismo en el diccionario general plantea un problema en cuanto a la definición que se adoptará. Las definiciones de este tipo de texto no se basan en los mismos principios que las de un diccionario especializado. En cada caso, los aspectos relevantes que han de presentarse al lector son diferentes. Lo que a un tipo de público resulta imprescindible puede ser innecesario y hasta entorpecedor del mensaje para otro. Piénsese, por ejemplo, en el registro de la voz azúcar: no sería conveniente definirla en un diccionario general - donde la definición podría ser: "substancia dulce cristalizable que para fines comerciales se obtiene principalmente procesando el jugo de la caña de azúcar o el extracto acuoso de la remolacha azucarera y refinándolos" - como se haría en uno químico - por ejemplo, "carbohidrato cristalino dulce $\left(\mathrm{C}_{12} \mathrm{H}_{22} \mathrm{O}_{11}\right)$ " - ni a la inversa, pues los elementos que interesan al especialista no son los mismos que los que interesan a quien no lo es. Precisamente una de las causas principales de muchos ataques contra las definiciones del diccionario académico (u otros generales) radica en el desconocimiento de esta necesaria diferenciación.

En especial, al diccionario académico se le reprocha que no recoge los términos científicos y técnicos (o que lo hace cuando ya han envejecido), y que los que registra aparecen con importantes deficiencias en la definición, en algunos casos "escandalosas"'.

De lo expuesto hasta aquí se desprende, por una parte, que 
no siempre tales reproches son justos (aunque hay que reconocer que en demasiadas ocasiones sí lo son) y, por otra, que por mucho que agudicen su sentido y sus métodos de trabajo, los lexicógrafos difícilmente están exentos de errores en su selección. La discusión acerca de si tales términos debieron incluirse o no, y acerca de la validez de las definiciones con que se registraron, es infinita, pues múltiples son los puntos de vista que se pueden adoptar, e inagotable la posibilidad del conocimiento y, en consecuencia, del surgimiento de nuevos vocablos y la desaparición de otros, de reajustes en los significados, etcétera.

Llegados a este punto, vale la pena traer a colación un elemento que, por ser tan evidente, se pasa por alto demasiado a menudo, tanto por quienes exigen la inclusión de tales o cuales voces, como por ciertos puristas y por las más variadas personas: la existencia de un vocablo (sea científico o técnico, sea de cualquier otra procedencia) no está determinada por su inclusión en un diccionario, sino por su uso real entre los hablantes; son ellos quienes otorgan carta de ciudadanía a las palabras, no los diccionarios y las gramáticas, que se limitan (o debieran limitarse) a registrarlas y describirlas. El hecho de que un término no esté contenido en el diccionario académico, por ejemplo, no puede significar otra cosa sino que a esa corporación no ha llegado la información correspondiente, o que la información llegada no justifica, a los ojos de los académicos, su inclusión en el inventario que se ha de dar a la luz. Pero no puede significar nada más, pues su condición de elemento de la realidad no puede estar dada por el reconocimiento oficial de una institución, por prestigiosa que ella sea.

No hay por qué dudar de que la Academia se esfuerza por acoger en su repertorio la mayor cantidad posible de términos científicos y técnicos generalizados. Con aciertos y con yerros, esa voluntad es evidente, sobre todo en la última edición (1984) del diccionario de la lengua. Se puede discrepar en muchos casos, pero no negar esa realidad. Inclusive, la Academia ha publicado recientemente un diccionario técnico. Sólo que ni puede ella incorporarlo todo al diccionario general, ni mucho menos hacerlo a la velocidad que sería deseable.

Una solución parcial, claro está, la proporcionan los diccionarios terminológicos por ramas de la ciencia o la técnica (los grandes y abarcadores diccionarios politécnicos adolecen no pocas veces del mismo mal que los generales). Pero en todos los casos siempre será posible encontrar que faltó o sobró algo. Salvo acaso en 
alguna rama muy específica del saber, con un inventario léxico reducido, nunca será posible encontrar el diccionario verdaderamente completo: todos están desactualizados al día siguiente de su entrada a la imprenta, por las razones apuntadas hasta aquí.

En definitiva, la conclusión válida es que hay que mantenerse alerta contra el fetichismo del diccionario, no exigir de él más de lo que puede aportar, ni otorgarle poderes que no tiene.

La única forma posible de mantener actualizado un diccionario es su automatización. Los bancos terminológicos automatizados aportan la solución futura para los problemas enunciados hasta el momento. El hecho de poder interactuar con la máquina, de alimentarla constantemente, permite al consultante obtener información con un máximo de actualidad. Estos "diccionarios electrónicos" o "automáticos" ya funcionan en muchos lugares, y los sistemas existentes se perfeccionan continuamente. Desde luego, todavía no están al alcance de cualquier individuo (generalmente funcionan entre instituciones, pues aún es un servicio caro), y para el hombre común (sea técnico o no) pudiera resultar más sencillo acudir a un diccionario impreso. De cualquier manera, los diccionarios automáticos no significan la desaparición de los tradicionales, sino un grado más alto de su desarrollo. Por lo pronto, a partir de la existencia de un banco terminológico automatizado se pueden imprimir diccionarios altamente actualizados en un tiempo muy breve, lo cual sí es una ventaja considerable para el consultante. En el futuro, además de que los "diccionarios generales" estarán cada vez más permeados de términos técnicos, su modo de presentación también conocerá cambios. El propio concepto de diccionario normativo, que dio lugar al nacimiento del académico, se transformará.

Con independencia de las innovaciones que puedan surgir, junto a los diccionarios (automáticos o impresos) meramente descriptivos y con vocación de exhaustividad, continuarán existiendo otros con matiz normativo, al menos para el vocabulario científico y técnico, como una exigencia del desarrollo de la ciencia y de la técnica. En la documentación técnica, en el intercambio de información, en la traducción automática y en la investigación, el uso de un léxico normalizado es actualmente una necesidad y lo continuará siendo en el futuro. (Precisamente por ello en muchos países existen comisiones nacionales de normalización que se encargan de determinar, entre varios términos sinónimos, cuáles se deben aceptar y cuáles se deben rechazar; en algunos lugares esta 
labor concluye con recomendaciones que pueden ser acatadas o no; en otros, como en Cuba, aparecen en documentos que tienen fuerza de ley.) Es decir, que, si bien el criterio preceptivo tradicional no tiene en verdad razón de existir, cierto grado de normatividad será siempre necesario para que en el lenguaje científico y técnico no se entronice una exuberancia de términos parásitos entorpecedores de la comunicación. Sólo que esta no será tarea del diccionario académico, sino de los diccionarios (automáticos o impresos) de normas terminológicas.

Rodolfo Alpízar Castillo Instituto de Literatura y Lingüística Academia de Ciencias de Cuba 